\title{
Determining strategies that predict physics identity: Emphasizing recognition and interest
}

\author{
Robynne M. Lock, ${ }^{1}$ Jordan Castillo, ${ }^{1}$ Zahra Hazari, ${ }^{2}$ and Geoff Potvin ${ }^{3}$ \\ ${ }^{1}$ Department of Physics \& Astronomy, Texas A\&M University-Commerce, Commerce, TX 75428 \\ ${ }^{2}$ Department of Teaching $\&$ Learning, Florida International University, Miami, FL 33199 \\ ${ }^{3}$ Department of Physics, Florida International University, Miami, FL 33199
}

\begin{abstract}
Although the number of students earning bachelor's degrees in physics has increased, the percentage of those degrees earned by women has not increased for more than 10 years. We use a physics identity framework to understand the factors that may impact physics career choice. Physics identity consists of three dimensions: recognition (perception of recognition by others), interest (desire to learn more), and performance/competence (perception of ability to understand). Our previous work has shown that recognition and interest are more significant predictors of physics career choice than performance/competence, and that women may require more recognition than men in order to choose physics careers. Therefore, teaching strategies that specifically target recognition and interest should be identified. Using data from a survey administered to a nationally representative sample of college students, we use regression models to determine which teaching strategies predict recognition and which strategies predict interest.
\end{abstract}

PACS numbers: 01.30.Cc, 01.40.Fk, 01.40.gb

\section{INTRODUCTION}

The number of students earning bachelor's degrees in physics has increased in recent years but has only barely surpassed the peak value of the 1960s [1]. This represents a fraction of a percent of all students earning bachelor's degrees nationwide. Additionally, the percentage of physics bachelor's degrees earned by women has not increased for 10 years and remains approximately $21 \%$ [1]. Hence, strategies to recruit more students into physics, in particular women, are needed. As students make their initial career decisions at the end of high school and beginning of college, we focus on strategies that can be implemented in high school physics. These strategies could potentially have a large impact because more high school students than ever are taking physics, and nearly half of those students are female [2]. Moreover, many women physicists report first becoming interested in physics while in high school [3]. We use a physics identity framework to understand the factors that influence students' career decisions.

Physics identity overall can be considered to be the extent to which a person sees herself or himself as a "physics person". Physics identity has been shown to correlate with physics career choice [4]. Our identity framework consists of three dimensions: recognition, interest, and performance/competence. Recognition is the extent to which a student perceives others (parents, teachers, peers) to see herself or himself as a "physics person". Interest represents a student's desire to learn more about physics. Performance/competence is a students perception of his or her ability to understand physics and perform well on tasks such as exams [4]. This identity framework was originally developed for professional scientists and consisted of the three dimensions: recognition, performance, and competence [5]. In adapting the framework for students, the dimension of interest was added
[4]. Additionally, factor analysis revealed that in students in early college, performance and competence are indistinguishable [6].

In previous work, we found that recognition and interest are more significant predictors of physics career choice than performance/competence. Additionally, we found that women require more recognition than men to experience the same effect on career choice. Typically, men have higher physics identities than women in all three dimensions [6]. While teaching strategies have been identified that correlate with physics identity [4], given the importance of recognition and interest, understanding strategies that may support development of recognition and interest specifically should be emphasized.

Many strategies have been hypothesized as methods of improving students' attitudes and achievement in physics. This includes studying the impact on identity, interest, motivation, and problem-solving ability. Little emphasis has been placed on recognition in particular; however, methods to increase interest have been explored. Hazari et al. found 7 strategies that are predictors of physics identity overall: conceptual understanding class focus, labs address belief about world, student comments/answers questions, student teaches classmates, discussion of currently relevant science, discussion of benefits of being a scientist, and discussion of female underrepresentation [4]. However, this work did not examine strategies for the individual identity dimensions separately [4]. Another method suggested to build identity is through helping students come to see themselves as experts who can use physics to improve people's lives. This is known as the development of critical science agency and can be achieved by creating opportunities for students to take on the role of teacher or leader and connect physics to their career plans [7]. Similarly, the incorporation of everyday life and real-world applications into instruction, class activities, and assess- 
ments can have positive effects on motivation, interest, and problem-solving ability and can also lead to a conceptual focus [8, 9]. Additionally, an intervention designed to show students that physics offers opportunities for creative thought and individual ideas was found to reduce students' negative attitudes towards physics [10]. Finally, student-centered active-engagement learning environments such as SCALE-UP have shown positive outcomes in attitudes, problem-solving ability, retention, and confidence $[8,11]$. In this work, we identify teaching strategies that predict recognition and interest specifically by performing regression analyses using national survey data.

\section{METHODS}

The data used in this study is drawn from the Sustainability and Gender in Engineering (SaGE) Project. $\mathrm{SaGE}$ is a large-scale national survey that was administered to students in introductory college and university English courses in Fall 2011. 6,772 students from 50 colleges and universities completed the survey comprising a nationally representative sample. Introductory English courses were chosen because, as a core course, a wide range of students, those with no interest in science and engineering and those with a strong interest, would participate. $100 \%$ of colleges and universities that were recruited returned surveys. The student response rate was $41 \%$. Survey items included questions about career goals, high school science experiences, sustainability, and science and math identity.

The survey items used in this work include physics identity items and questions about high school physics experiences. We previously conducted a factor analysis to construct variables representing recognition and interest from physics identity items [6]. Items about high school physics experiences included questions about: Connections to everyday life; classroom environment; engineering/science careers and applications; demonstrations, laboratories, and projects; use of technology; assessment; and conceptual understanding. These items were chosen because they are teaching strategies that high school physics teachers have control over and because of their potential for impact on recognition and interest.

We performed linear regression analyses to identify teaching strategies that predict recognition and teaching strategies that predict interest. Only significant items were retained in the final models.

\section{RESULTS}

Table I shows the models predicting recognition $(\mathrm{R})$ and interest (I). Model $\mathrm{R}$ explains $21 \%$ of the variance, and Model I explains $23 \%$ of the variance. Several teaching strategies were found to be positive predictors of both recognition and interest. This overlap is to be expected given the high correlation between recognition and interest. These strategies are: Topics are relevant to student's life; student asked questions, answered questions, and made comments; spoke with male engineer/scientist visitor; student picked the topic for labs/projects; covered engineering careers, stages, and options; questions required new insight or creativity; and required conceptual understanding. Two strategies were found to be negative predictors of both recognition and interest. These strategies are teacher called on students (nonvoluntary) and required memorization.

Two strategies correlated positively only with recognition. These are projects/labs addressed a community/family issue and questions required graphing. The two strategies that correlated positively only with interest were participated in outdoor activities and questions involved data presented in tables.

Gender interaction effects were found to be significant in both models. Questions involving data presented in tables had a larger effect for males than for females on both recognition and interest. The student asking questions, answering questions, and making comments had a larger effect on males than females on recognition. The student designing or building something had a larger effect on females than on males on interest.

\section{DISCUSSION}

Supporting development of recognition involves creating opportunities for students to feel recognized by their teachers, peers, or parents as physics people. Building interest means increasing students' desire to learn more about physics and enjoyment in learning the subject. Increasing recognition and interest can be achieved through a variety of teaching strategies in the high school physics classroom. Our regression models show that in many cases the same strategies that correlate with recognition also correlate with interest. The strategies identified are consistent with several suggested methods for improving students' attitudes towards physics including offering opportunities for students to be the expert, making connections to careers and real-world applications, allowing for creative thought, and using student-centered activelearning environments.

Strategies that give students the opportunity to be leaders and experts who can improve the world and strategies that make connections to careers have the potential to impact identity through the development of critical science agency [7]. Several of the strategies found to positively correlate with recognition and interest may function through this mechanism. These methods are: Students picking the topic for projects or labs, projects or labs addressing a community or family issue, speaking with a male engineer/scientist visitor, and covering engineering careers, stages, or options. All of these impacted both recognition and interest except for projects 
TABLE I. Regression models predicting physics recognition $(\mathrm{R})$ and interest $(\mathrm{I}) .{ }^{*}: \mathrm{p}<0.05 ; * *: \mathrm{p}<0.01 ; * * *: \mathrm{p}<0.001 ;$ ns: not significant.

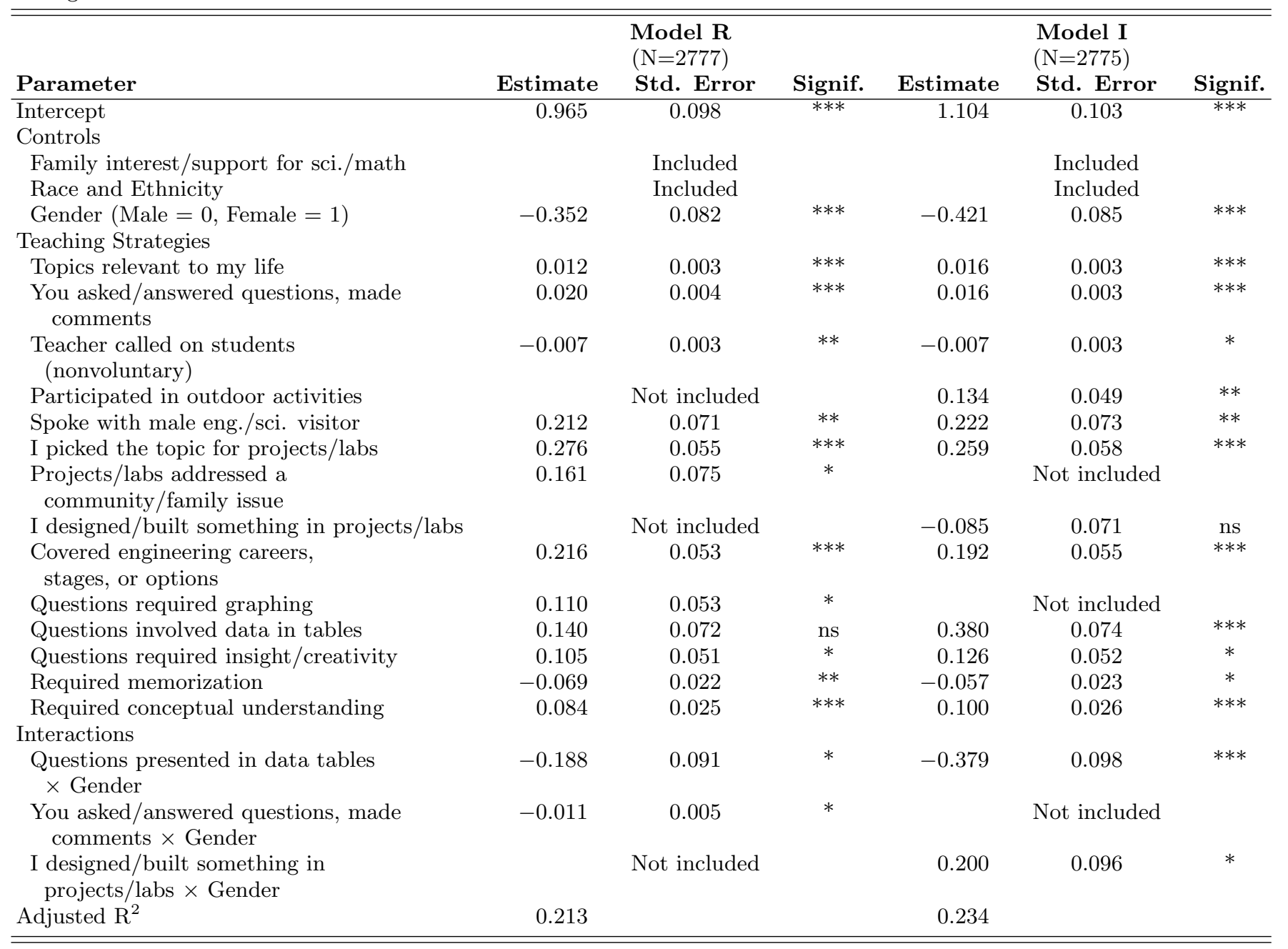

or labs addressing a community or family issue which only had an effect on recognition. Speaking with a female engineer/scientist visitor was not significant, possibly because this is a rare occurrence.

A number of the strategies found to correlate with recognition and interest can be understood as methods of making connections of physics content to real world applications and everyday life. Such connections have previously been examined for their effect on interest and other related outcomes but not on recognition $[8,9]$. The relevant identified strategies are: The inclusion of topics relevant to the student's life, projects or labs addressing a community or family issue, speaking with a male engineer/scientist visitor, and covering engineering careers, stages, or options. Note that there is overlap between strategies that may support identity development through critical science agency and strategies that may support recognition and interest development through connections to everyday life. Additionally, this method is consistent with the previous finding that labs that address beliefs about the world have a positive effect on physics identity [4].

Another possible way that these identified strategies may achieve their effects on recognition and interest is through showing that physics offers opportunities for creative thought and development of new ideas. Physics has been found to be associated with a lack of creativity, and a reading activity designed to counter this association reduced negative attitudes [10]. Strategies that positively correlate with recognition and interest that may also counter this association are: Questions requiring new insight or creativity, students picking the topic for projects or labs, and the student asking questions, answering questions, and making comments.

Methods identified that correlate with recognition and interest are also consistent with the finding that studentcentered active learning environments can improve attitudes $[8,11]$. The most relevant identified method is the student asked questions, answered questions, and made comments. This agrees with the previous result that student commenting and answering questions has a positive effect on physics identity overall [4]. The negative 
correlation of the teacher calling on students nonvoluntarily with recognition and interest may at first seem contradictory because calling on students is a method of engagement. However, this may create a threatening rather than comfortable environment for students' active participation. The importance of a comfortable learning environment for the students has been emphasized [8].

Conceptual understanding has long been a focus of physics education research, and a focus on conceptual understanding has been found to have a positive effect on physics identity overall [4]. The present finding that requiring conceptual understanding is supportive of both recognition and interest agrees with these previous results. The negative effect of requiring memorization on recognition and interest also agrees because developing deep conceptual connections can in certain cases be incompatible with an overemphasis on basic fact memorization.

A strategy found to have an effect on interest but not recognition is participating in outdoor activities. A reasonable assumption would be that outdoor activities make physics class more enjoyable and thus more interesting. However, a mechanism for how these activities would create opportunities for recognition is not immediately apparent.

Assessments can emphasize to students what knowledge and skills are valued by their teacher. Two assessment strategies correlated with only recognition or only interest. Questions requiring graphing correlated with recognition, while questions involving data presented in tables correlated with interest. The reason that one impacts recognition but the other impacts interest is not clear without knowledge of how these questions were implemented. One possibility is that these questions are related to lab activities. As previously mentioned, labs that address beliefs about the world have a positive effect on physics identity [4].

Three strategies exhibited gender interactions. Questions involving data presented in tables was the source of a gender interaction effect for both recognition and interest. This type of question was found to have a more positive influence on males than females. Interpreting this result requires knowledge of the context. Another strategy with a gender interaction was the student asking questions, answering questions, and making comments. This strategy had more of an effect on recognition for males than females reflecting that males and females may experience interaction in different ways. Finally, the student designing or building something had a larger effect on interest for females than males. This effect may arise because typically boys have more experience with technology outside of class than girls do [8], so this type of experience is more important to provide for girls. However, there was no main effect for this strategy.

\section{CONCLUSION}

Because recognition and interest predict physics career choice, we identified several teaching strategies that correlate with these identity dimensions. We focused on strategies that can be implemented in high school physics classes because students begin making their initial career decisions during this time and because increasing numbers of students, a substantial fraction of whom are women, take high school physics. Many strategies have effects on both recognition and interest, but a few only affect recognition or only affect interest. We also found that in some cases strategies vary in effectiveness by gender. The identified strategies are consistent with several suggested methods for improving students' attitudes about physics including students taking on the role of expert, emphasizing career connections and realworld applications, providing opportunities for creativity, and creating a student-centered active-engagement classroom. While analysis of survey results provides limited insight into how these strategies are implemented or the broader classroom context, future work can expand on these results through case studies of classrooms in which these strategies are implemented.

\section{ACKNOWLEDGMENTS}

The authors thank the National Science Foundation (NSF GSE 1036617) for funding of the SaGE Project.
[1] P. J. Mulvey and S. Nicholson, Physics bachelors degrees, Tech. Rep. AIP Research Center (2012).

[2] S. White and C. L. Tesfaye, Female students in high school physics, Tech. Rep. AIP Research Center (2011).

[3] R. Ivie and S. Guo, Women Physicists Speak Again, Tech. Rep. AIP Research Center (2006).

[4] Z. Hazari, G. Sonnert, P. M. Sadler, and M.-C. Shanahan, J. Res. Sci. Teach. 47, 978 (2010).

[5] H. B. Carlone and A. Johnson, J. Res. Sci. Teach. 44, 1187 (2007).

[6] R. M. Lock, Z. Hazari, and G. Potvin, AIP Conf. Proc. 1513, 262 (2013).
[7] S. J. Basu, A. Calabrese Barton, N. Clairmont, and D. Locke, Cult. Stud. of Sci. Educ. 4, 345 (2008).

[8] P. Labudde, W. Herzog, M. P. Neuenschwander, E. Violi, and C. Gerber, Int. J. Sci. Ed. 22, 143 (2000).

[9] G. Taasoobshirazi and M. Carr, Educ. Res. Rev. 3, 155 (2008).

[10] U. Kessels, M. Rau, and B. Hannover, Br. J. Educ. Psych. 76, 761 (2006).

[11] R. J. Beichner et al., in Research-Based Reform of University Physics, edited by E. F. Redish and P. Cooney (AAPT, College Park, MD, 2007). 